\title{
INFLUENCE OF THE PERSONAL SUBJECTIVITY ON FORMATION OF COMMUNICATIVE LEADERSHIP
}

\section{Berkimbayev Kamalbek}

Doctor of pedagogical sciences, professor, "Pedagogical sciences" department, «Humanitarian sciences» faculty, International Kazakh-Turkish University by Hodja Ahmet Yassawi, town Turkestan;

Sultanmurat Moldir

$\mathrm{PhD}$ student, "Pedagogical sciences" department, «Humanitarian sciences» faculty, International Kazakh-Turkish University by Hodja Ahmet Yassawi, town Turkestan;

Yersultanova Gaukhar

PhD student, "Linguistics" department, «Humanitarian sciences» faculty, Kazakh Pedagogical University by Abay, town Almaty;

Kastaev Serik

PhD student, "Pedagogical sciences" department, «Humanitarian sciences» faculty, International Kazakh-Turkish University by Hodja Ahmet Yassawi, town Turkestan;

Annotation. The reflection of leadership in formation of personal physical, psychic, intellectual, professional development, intelligence, senses, volition at the «psychology»level was considered in this article. The definitions as leader and leadership, person was widely explained, the importance of person role in formation of communicative leader was described. Also various methods of teaching communication in the methodical book to determine the role and the place in formation as a subject of teaching activity.

Key words: leader, leadership, person, communication, subject, subjectivity, method, teaching. 


\section{ISPEC International Journal of Social Sciences \& Humanities \\ E-ISSN: 2717-7262}

Vol: 3, Issue: 1, 2019

In communication the issue of personal factors puts the investigation of the subjectivity development patterns in the foreground: a) relation of the author and the listener to the discussion point; b) to oneself; c) to the other; d) self-reflection as a method of control of own speech and the prospect of correcting own manner of speaking.

A leader (person in charge) starting from the person - not appointed by top,

1) organizer and inspiratory of the staff, 2) a group member possessing the highest sociometric and communicative status («one of us», - like the most ones, «our the best»), 3) more respected person known as a leading role while taking group decisions and while organization of joint works for achieving the goals.

«A profession leader - it is a person capable of influencing on the other to integrate the joint professional activity. A leader regulates the interrelation in group, keeps the values of the professional group during the group relations, influences on the formation of the group values and means them to a certain extent» [1]. According to the opinions of the American investigators of the Higher educational establishment problems the main quality of the professional leader is the specific definition of goals, skills to form them and skill to present the group due to the specific situation and to the clear conscious prospect.T.M. Balykhina states the following three types of the professional leadership: 1) business; 2) intellectual; 3) leadership in communication. In particular the communication is an integral part of the leader's activity. Communication is estimated as a capability of receiving and giving information in order to achieve the desired and exact results. It is no coincidence that the leader is called as «a power communicator».

At the present time there are different methods to classify the leadership not only to define it: 1) «instrumental leader», «expressive leader» (due to the activity area);

2) «situational leader», «universal leader» (due to the activity type); 3) «inspiratory-leader», «executor-leader» (due to the peculiarities while participation in group interaction).

Actually, the leadership - not only pedagogical but also the social and psychological issue. A base note of the social psychology is an explanation of position diversities of the same group people due to their relation to each other and to the group activities. Although the problem of developing the 


\section{ISPEC International Journal of Social Sciences \& Humanities}

E-ISSN: 2717-7262

Vol: 3, Issue: 1, 2019

leadership position of the person concerns not only the philosophers and psychologist, it always attracted the attention of the teaching staff too.

The analysis of the psychological-pedagogical book allows to do conclusion that the present methods of leadership investigation is distinguished by three methods of the base variables: 1) leadership skills;2) leadership behavior; 3) case of leader action. In the meantimea particular attention is paid to the description and behavior of the followers.

Position of the M.I. Rozhkov that the leader-«makers» (attempting for work) and the leader«breakers» (attempting for own benefit to show themselves) is interesting, he considers the leader as capable of the following: a) leading; b) inciting to work; c) influencing on the entourage very hard[2].

The scientists rest upon the following while forming the pedagogical system of developing the leadership position: a) perfect facts about the leadership and leader; b) development of leaders in order to teach; c) selection of students; d) determination of diagnosis characteristics of preparation level of being a communicative leader.

Main methodical issue -making a sample of teaching for forming leadership qualities and which should be developed in future not formal adaptation of the students to the truth[3].

It is to be noted that the terms in the domestic teaching experience are considered as a synonym because of the connection with leadership communication: «leadership ability» and «communicative ability». Certainly, the leadership — is a connecting specification of the person consisting of the communicative culture as an obligatory component, until digesting it is uncertain to achieve authority and leading position in group.

A leadership potential should be considered as connecting personal quality, the characteristics of the detection are the following: 1) high motivation which will be the work subject; 2) developed intellectual, communicative, suggestive peculiarities; 3) creativity. The student period differs by the high motivation to possess leadership skills, by the active social orientation of the activity, the students wants to be confident in himself and to feel the belonging in an important activity, he has a right to learn to show himself, to be the valued member of the group due to his estimation. However, there is no entire communicative system to form the communicative leader in the higher professional education system: it offers students to learn the modern norms of the pedagogics, communication 


\section{ISPEC International Journal of Social Sciences \& Humanities}

E-ISSN: 2717-7262

Vol: 3, Issue: 1, 2019

psychology, but the fragment knowledge doesn't help to be the competent during the professional leadership communication.

Necessity in preparing the method of developing the leadership qualities on the basis of the formation of the communicative competence. The modern student possessing the known intellectualvolitional advantages over the other members of the group, contended to be the leader, he should have communicative skills, should be able to organize the structural interpersonal interaction.His leadership is determined by influencing on the other members of the group in the direction of achieving the goals setduring the joint execution, joint authorship, partnership. It creates the necessity in making the technological sample to provide the pedagogical situations for developing the leadership qualities during the learning process at the higher educational establishment by identifying the possibility of developing the leadership skills.

The management smart people of the country are trained at the higher educational establishmentand the future management staff depends on the training quality, if they will be an initiator, a mediator, a leader, a supporter of the innovative reorganizations in the country. Nowadays, the teaching is defined as a proper space where the people can function. The method of human in teaching matter rests upon the communicative philosophy. As for our investigation, it means text-based, unitedness, productivity, reflexivity. The problem of individual to be the individual in teaching activity of the communicative system of the higher professional teaching is based on the leadership development (group, team) within the joint mind function area.

Using the definitions «a leadership» and «a leader» extensively confirms its necessity and extensive use on the one hand, the polysemanticity of explanations on the other hand, by transforming them into the nice and monosemic epithet. Mentioning that there is nounique scientific explanation of this definition, the uncertainty of its explanation, contradiction, non-uniqueness disturbs the investigators. It is required to join the results of investigation conducted due to the positions of various scientists in order to understand entirely the human as a process owner or as possessing leadership qualities. Leadership is reflected in the formation of physical, psychic, intellectual, professional development, intelligence, sense, solvability on the «psychology» level.The leadership potential enables a leader to express valuable dominants of the team which acts as a set of person and activity and which should achieve the common goal.Leadership potential — it is a psychologic synthesis of the combining, 


\section{ISPEC International Journal of Social Sciences \& Humanities \\ E-ISSN: 2717-7262}

Vol: 3, Issue: 1, 2019

multilevel education, psychomatic resource of the person: biological, psychological, intellectual,social, mental, creative, innovative. Leadership potentialis demonstrated in the governing activity through the partnership with the group members, speech culture in modifying joined activity.

At present time, the definitions leadership and leaderbeing equal with definitions subjectivityand subject have leading positions in adjacent sciences investigating the human and his speech. Moreover, the special investigations and many editions cannot reply the main methodic question- is it possible to develop the leadership qualities or it is inherited. Meaning of the personal quality of special kind connected with the human's activity having the clearly shown orientation in reorganization activity due to changing himself was traditionally fixed in humanistic philosophy and psychology as a subject(A. Maslou, G. Opport, K. Rogers, S.L. Rubinshtein, D.N. Uznadze, M. Fuko and others). We denote that the communicative competence is number one among its systemic components of the system among, having specified the leadership as a kind of the highest level of the professional competence.A communicative competence includes communication, information sharing, and establishment of purposeful relations with the participants of the leading discourse, the activity organization is included on the basis of partnership in communication mode. Communicative imperativeness of present education is not only understanding the humanity principles and also understanding of «insufficiency and impossibility of sole consciousness to yourself: a human becomes himself only through other people or with the assistance of others. The one entering the interrelation process is determined with principal impossibility of personal symmetry and achievements of the subjectivity, because it is impossible «to look through, determine and say previously» the person without his consent, «on the side», «a real life of the person is accessible only for communicative passing which is opened freely and responsible» [4].

In communication except transforming the another it is important to transform yourself to be capable of understanding knowledge and the lack of knowledge.Communication - it is a meeting of person with unfamiliar.An unfamiliar one maybe the culture, nature, human, himself. The result of such meeting is establishment of forming connections on the basis of the cross-pollinationand positive personal development. Communication - is a proper start of the communication and constructive potential of the interpersonal relations development. In this area, on the one hand is the ethic deficiency of the communication types violating the rules of communication and estimationof the communication 


\section{ISPEC International Journal of Social Sciences \& Humanities}

E-ISSN: 2717-7262

Vol: 3, Issue: 1, 2019

as a meaningful method of communication (authoritative, manipulative, formal), on the other hand the necessity of forming the preparation to communicate - variously developed different skills and capabilities of different people(communicative competence of the person), separately, maybe arisen as a special stated pedagogical problem. At that timethe subjectivity should be the basic meaning of developing as a true goal of the humanitarian knowledge and to give opportunity to human to define himself.

V.Frankl considered that the main issue of teaching not for «being satisfied by providing traditions and knowledge», but for «development of capabilities giving opportunity to people for finding out unique meanings» [5].

The subjectivity of the person is not only in critical thinking concerning the ususal truth, not in capability of protecting own opinions, it is in necessity of forming its life position.

There are various methods in the methodical book to determine the role and the place of communication in formation as a subject of teaching activity. In several modern conclusions offered by the present science, for instance, according to the philosophy of V.S.Bibler's conclusion the human is a culture subject of rational being which is capable of self-determining within the culture, communication process. Besides, the human at his activity due to the acquiring the world, due to the philosopher's opinion cannot still be the culture subject.

Obviously, the intellectual powers, life experience and professional knowledge of teacher and the student are not the same,the last one - is not always a partner of the communication, but it assists in greatly understanding of the personality of forming teaching, in hearing it, in unveiling the creative potential of the student who is ready to understand the importance of received information for him, in trying to stop being a puzzlement for him. Unfortunately, as an effective object of teaching to officially announce the communication; actually the education system is mostly stay as monologic: the student is not a participant of the cognitive process, because the knowledge is given to him in form of suitable set for the teacher. Disengagement problem of the student from learning process and rom knowledge - is one of the present education problems which prevent the formation of personality. Awareness does not make the human competitive - knowledge continue to stop being the part of education. 


\section{ISPEC International Journal of Social Sciences \& Humanities}

E-ISSN: 2717-7262

Vol: 3, Issue: 1, 2019

At the same time, I.Kant specified the cognition subject as «a former», maker of scientific and other different knowledge, it is known that he noted the hopelessness of developing the cognition process with «human's face», here he noted three questions: what can I know? What can I do? What can I believe in? These questions lead for putting the main question-who is the human?Higher education cannot keep out of searching the suitable methods to «develop» the human who needs knowledge for himself. Nowadays, it is no secret that a human possess and lost himself. It tries to direct, to understand, to see the process of self-formation within the pedagogical science and experimental communication, because communicative style of interrelation with yourself in the meaning of solving important personal and professional problems with the world gives opportunity to the student to take position of interested subject for taking rise himself,-it is firstly, secondly-the responsible relation to own knowledge. Firstly, the communicationteaches the human to solve problems by agreeing with himself as an («outside» and «inside»)experience of cooperation with the world and yourself.The human passes the definite stages of actions by executing the communicative experience: «inside and outside» connection, empathy, setting the reflection. He searches himself in others, because «the truth is not arisen and doesn't stay in separate people's mind, it is arisen between the people.»[5].

Finally, the analysis of scientific books and education process influences on the purposeful execution of two level system of higher professional education, applicability of personality development and on formation of communicative leadership,it confirms the necessity of methodological and methodical searches to make a combined sample of teaching students as future communicative leaders.

\section{References}

1.BalykhinaT.M.MethodsofteachingRussianasnot native (new): Work book. $2^{\text {nd }}$ edition, rev. - M.: 2010. - 188 p.

2.YespolovB.T.Phenomenon of political leadership of President of RKNazarbayev N.A.: dis. ... candidate of political sciences. - Almaty, 2010.- 128 p.

3.Maksimova R.A. Leadership and skills of leading efficiency of the head. -Saint Petersburg : Peter, 2007.

4. Yermentayeva A.R. High school psychology: text book. - Almaty: 
ISPEC International Journal of Social Sciences \& Humanities

E-ISSN: 2717-7262

Vol: 3, Issue: 1, 2019

Dauir, 2012. - 492 p.

5. KorepanovaM.V. Philosophy.Psychology.Pedagogics // New series. Saratov University Review. - 2009. - T.9, №4. 